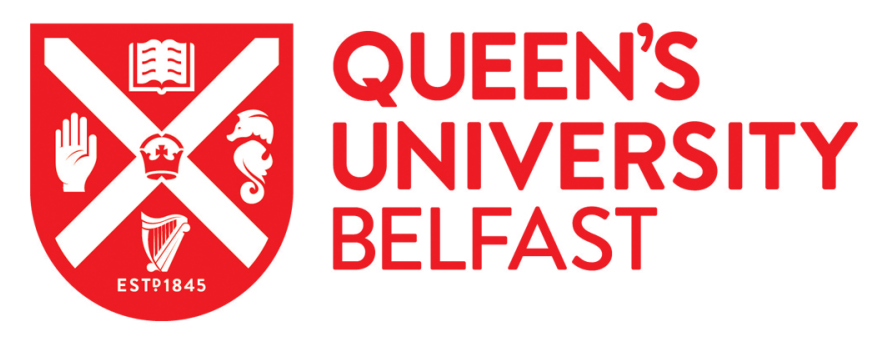

\title{
Sex Education: Challenges and Choices
}

MacKenzie, A., Enlsin, P., \& Hedge, N. (2017). Sex Education: Challenges and Choices. British Journal of Educational Studies, 65(1), 27-44. https://doi.org/10.1080/00071005.2016.1232363

Published in:

British Journal of Educational Studies

Document Version:

Peer reviewed version

Queen's University Belfast - Research Portal:

Link to publication record in Queen's University Belfast Research Portal

\section{Publisher rights}

(C) 2016 Society for Educational Studies.

This is an Accepted Manuscript of an article published by Taylor \& Francis in British Journal of Educational Studies on 28th September 2016, available online: http://www.tandfonline.com/10.1080/00071005.2016.1232363.

\section{General rights}

Copyright for the publications made accessible via the Queen's University Belfast Research Portal is retained by the author(s) and / or other copyright owners and it is a condition of accessing these publications that users recognise and abide by the legal requirements associated with these rights.

Take down policy

The Research Portal is Queen's institutional repository that provides access to Queen's research output. Every effort has been made to ensure that content in the Research Portal does not infringe any person's rights, or applicable UK laws. If you discover content in the Research Portal that you believe breaches copyright or violates any law, please contact openaccess@qub.ac.uk. 


\title{
Alison MacKenzie, School of Education, Queen's University Belfast
}

\section{A.Mackenzie@qub.ac.uk}

\author{
Penny Enslin, School of Education, University of Glasgow \\ Penny.Enslin@glasgow.ac.uk
}

\author{
Nicki Hedge, School of Education, University of Glasgow \\ Nicki.Hedge@glasgow.ac.uk
}

\section{Sex Education: Challenges and Choices}

\begin{abstract}
Noting public concern about sexual exploitation, abuse and sexualisation, we argue that sex education in the United Kingdom needs revision. Choice is a feature of current sex education policy and, acknowledging that choice can be problematic, we defend its place in an approach to sex education premised on informed deliberation, relational autonomy, a particular view of personhood and moral literacy. We argue, however, that choice and the approach outlined must be located in the realities of young people's lives.
\end{abstract}

Keywords: Sex education, choice, exploitation and abuse, autonomy, moral literacy, sexualisation

As they follow exposés of sexual abuse within some of Britain's key institutions and cities, as well as revelations of widespread exploitation perpetrated by familiar media figures, the British public are talking about sexual exploitation and sexual behaviours. In 2012, in a case that brought the scale of sexual exploitation to public attention, nine men were found guilty of participation in a gang that sexually exploited under-age girls in Rochdale. Although 50 young people, mainly girls, were thought to have been affected by, or at risk from sexual exploitation, no further action had been taken because the young people were 'making their own choices’ and deemed to be 'engaging in consensual sexual activity’ (RBSCB, 2012, p.9). Moreover, the behaviour of the young Rochdale women was regarded 'as problematic, and essentially wilful' (RBSCB, 2012, p.11). The assumption that those abused had chosen to collude in their own exploitation seems to have provided an excuse for institutional 
failure to intervene. Such cases represent the extreme end of a continuum of a sexualised culture, but sexual abuse is widespread (Berelowitz et al., 2012). Hence it is not surprising that, in the United Kingdom and beyond, there is political and public concern that a crisis about sexual attitudes and behaviour requires an educational response. Sex education is on the political and educational agenda. ${ }^{1}$

Noting that young people themselves all too frequently deem sex education to be 'too little, too late and too biological' ${ }^{2}$, we focus here on an educational response appropriate to today's sexualized landscape. With reference to a number of official reports, reviews and inquiries, we propose that current approaches to sex education have failed to address shifts in sexual attitudes and behaviour. We may also be amidst a 'backlash against gender equality of staggering viciousness' (Smith, 2013, p.11). Sex, sexual abuse and sex education raise complex issues of autonomy and what might constitute 'good' rather than 'right' choices. We argue that sex education in the UK needs revision with particular attention to supporting young people to make informed choices from amongst the range of possibilities they will encounter. These revisions could include discussions about rights, agency, respect for others and what it means to consent. Additionally, pleasure and desire, following Allen et al $(2014)^{3}$, merit further attention as a counter-balance to the debates and media moral panics over the apparently premature sexualisation of young girls in particular.

While arguing for better support to enable young people to make informed choices, we also note three problems with choice. Firstly, claiming that the young people who were abused were not victims because they had made 'lifestyle choices' is morally and legally derelict. Failure to respect young people by protecting them from sexual exploitation and abuse is to collude in the violation of their autonomy and personhood, and such violation cannot be justified on any grounds. Secondly, we propose that affording parents and carers the choice to withdraw children and young people from education about sex may deny those young people the opportunity to make their own informed, autonomy-enabling choices. Thirdly, we demonstrate that while current sex education policies point to informed choice, those policies and their implementation may be narrowly and moralistically framed. They may assume a 'right' choice ${ }^{4}$ in a context that fails to be of much relevance to the lives of young people today.

Initially we explore a conceptualisation of choice and sex education premised on relational autonomy. Secondly, we sketch the current landscape, referring to concerns about 
sexualisation, violence, and the commercialisation of sex. Thirdly, we outline the current approach to sex education in the UK and, finally, we recast sex education in the light of our analysis. Whilst it would be naive to assume that education alone, including sex education in schools, could adequately resolve the problems alluded to above and further detailed below, we suggest that education about sex requires urgent attention. Following Oerton and Bowen (2014, p.680), we recognise that 'education on various aspects of sexualities and sexual relations is fraught and uneasy territory', but if young people are to become 'active, empowered and well-informed sexual citizens in the future' (p.690), then that territory demands re-interrogation.

Choice, autonomy and context

In this preliminary account of choice we outline a view of choice as a constituent of autonomy framed in a particular view of personhood. We move, then, to a discussion of relational autonomy to defend the role of choice in sex education from accusations of atomistic individualism. Feminist work has done much to retrieve autonomy from its perception as metaphysical, individualistic and economistic (Friedman, 2003; MacKenzie, 2014). However, what incites disagreement, even suspicion and dismissal of autonomy, is that its conceptions vary according to the normative framework and view of personhood deployed, and to the values and political orientations to which one is committed. We locate the exercise of autonomous choice in a liberal conception of personhood in which each human being is regarded as an end in her own right, worthy of respect and dignity, and equal to others. Having the capacity to choose, to make reasonable and meaningful choices in important areas of one's life, including sex and sexuality, is important if all are to enjoy extensive and basic liberty in ways that are compatible with an equivalent liberty for others (Rawls, 1971). To be a person who has the capacity to make choices, and who can take responsibility for those choices, is constitutive of what it means to choose a life plan that reflects a person's chosen values, aspirations and goals. However, autonomy requires control over one's circumstances. If autonomy is about 'being oneself', 'being true to oneself', 'thinking for oneself' (Friedman, 2003, p.3), then the agent will be critically selfreflective with regard to her desires, wants, wishes, and aspirations. What it means to make a choice, though, will depend on a range of diverse circumstances: the options available, the desirability or instrumental value of the choice, and the availability of information or education. In making choices, consent or dissent must not only be possible, but morally meaningful and this, of course, is highly relevant for sexual choices. Coercion, the condition whereby what a person wants is obtained by verbal, physical or emotional pressure or threat 
so that the person doing the choosing has no reasonable choice between doing what the coercer wants and facing a greater harm, means the chooser is unfree. Oppression and coercion that disable a person from following her own plan of life will stifle the conditions that enable autonomy, deforming desires and wants, damaging concern for self, and limiting the conditions in which authentic or informed choice can take place.

But what does it mean to choose and make informed choices about sex as an autonomous being whose choices entail equal liberty and respect for others? Because we have a relationship with others and ourselves autonomy is relational and socially-rooted (MacKenzie and Stoljar, 2000). The autonomous person is concerned for others. She is 'other-regarding', as respectful of the dignity and moral worth of others as she is respectful of her own dignity and value as a person. Such relational autonomy, premised on a socially embedded conception of agency, recognizes that an individual's identities and values will be developed in, and influenced by, relationships and her social context, and she may internalise oppressive or misogynistic norms. A young woman's choice to have sexual intercourse, or to text a nude image of herself, will likely be influenced by what she regards as the norm, understood as behaviours which exhibit some degree of regularity and which refer to social expectations of cultural behaviour (Blackman, 2004). Differences in norms may give rise to disagreement between a dominant group, including policy makers in sex and relationships education, seeking to impose one set of norms on a subordinate group, young people in receipt of such education, who may view their behaviours as equally norm based (Blackman, 2004, p.138). Significantly, for the sexual abuse and exploitation to which we shall refer, autonomy will be violated or stifled in exploitative, abusive or oppressive relationships and contexts. Informed choice about sexual behaviours will entail respect for the dignity of the other and oneself, recognition of and sensitivity to one's own and the other's vulnerability, consideration of the wellbeing of the other person. Informed choice will also result from questioning norms and social expectations.

Sex and relationships education (hereafter SRE) needs to confront the complexities of such choices in the contexts in which young people today find themselves. Insisting that individual choice and experience entails that young people's 'capacity to shape their own meaning ... cannot be separated from the social structures which regulate that individual's roles, abilities, opportunities and claims to authority', Shannon and Walker (2015, p.648) confirm the importance of focussing on the sexual autonomy of young people. Choice, understood as an element of relational autonomy, inseparable from social structures and the 
social milieu of young people, will include attention to both good and bad sex. It will position young people as human beings who seek pleasurable relationships if sex education is not to be as 'superficial as the kind of sex these curricula are trying to prevent' (Lamb et al., 2013, p.316). Sex education based on the autonomy of persons as outlined here follows Mosher (1989, p.504) in justifying sexual liberty without moral relativity or anarchy. Rather, sex education should educate young people to be 'sexual citizens’' (Lamb, 2010) who understand the importance of individual human rights, their own and others, consent, mutuality, respect and the dignity of the person in order to understand what it means to make a choice based on moral literacy. The World Health Organisation (WHO, 2009), for example, declares that sexual wellbeing requires a 'positive and respectful approach to sexuality and sexual relationships' in which it is possible, without coercion, discrimination or violence, to have 'pleasurable and safe sexual experiences'. One approach to sex education, then, would be to help sexually autonomous citizens understand that they have a basic human right not only to consent to sexual activity but also to refuse it.

Illustrating this claim through an exploration of contemporary examples that demonstrate the complexities of choice, our starting point is Archard's (2000) influential argument about sex education. It is the role of schools, claims Archard (2000), to help create individuals who can make 'free, autonomous choices as to how they want to lead their lives' (p.37). Anticipating elements of the official reports we outline in the following section, Archard (2000) observed that sex education has to contend with both a sexualised society and with confusion about our understanding of childhood sexuality. Noting that many report regretting having sex young, claiming their first sex 'was unwanted and even forced' (p.5), the urgency of Archard's concern with 'precocious sexual activity' (p.4) has since grown and shifted focus. ${ }^{5}$ There have been a number of reports, such as the high profile and contested Bailey (2011) and Papadopolous Reports (2010) we cite here (and see Buckingham et al, 2009), which have expressed concern about the sexualisation of society. Young people's sexual desires and pleasures have been commodified by capitalism, according to Allen et al (2014), and concern about the harms of premature and precocious sexualisation seems widespread ${ }^{6}$. However, that concern frequently focusses on the links between a sexualised culture and a range of negative impacts including educational achievement and eating disorders (Papadopoulos, 2010; Coy and Gardner, 2010). Young girls are portrayed as 'loud' and 'caricatured' (Renold and Ringrose, 2011). They wear padded bras, g-string underwear and playboy clothing (Allen et al, 2014, p.3). While these reports draw attention to corporate practices that sexualise girlhood, they do so in ways, as 
Renold and Ringrose (2011, p.390) comment, that ‘draw moral boundaries around (hetero)normative and age-appropriate notions of girlhood sexuality'. As a result, what are deemed to be acceptable and unacceptable desires and practices become 'isolating and regulating' (Renold and Ringrose, 2011, p.390). Other harmful effects of an over-sexualised society include the creation of moral panics with their 'overemphasis on protectionism, victimization and objectification', panics which ignore girls' sexual agency, rights and pleasure, reinforcing the gendered binary of 'active, predatory male sexuality in contrast to girls’ non-agentic sexuality’ (Renold and Ringrose, 2011, p.391).

Accordingly, Archard's related observation that sex education is under-specified and underresourced is highly pertinent today. We share Archard's view that while sex education should provide young people with the facts to make choices, facts alone are unlikely to enable young people to make informed considered choices. Information based or 'Just say no' type campaigns which overly focus on the negative consequences of sexual behaviours tend to be ignored by young people who may already understand the risks and pleasures (Blackman, 2004). As Blackman (2004, p.152) notes, 'informed choice’ in school based information programmes is, in actuality, a 'pre-established' no. An autonomous, informed chooser, on Archard's account, will not make choices based on what others do, or simply because she is told she ought or ought not to do something (p.40). Confident of her own choices, Archard's autonomous chooser will resist both peer and adult pressure because it is her own choices that express her wishes and preferences, and because those choices matter to her. However, and as we shall see, such an account asks a great deal of an individual's capacity to make choices from the panoply of possibilities in today's context. As our examples will indicate, peer pressure may have changed and support from the community has not always been available for young people who have been coerced into sexual behaviours they did not choose. Moreover, those adults from whom all young people might reasonably expect support, including education about sex, may not be aware of, or prepared to acknowledge, the situations in which, at best, young people make sexual choices based on desire and agency, and, at worst, in which they are subject to coercion and abuse.

In the sexualised landscape we outline in the following section, effective sex education ought to depend on what information is needed, on providing support and on teaching young people to exercise choice that promotes their flourishing. Stressing the importance of sex education to 'work with, and not against the grain of the social realities in which young persons find themselves', Archard (2000, p.13) prompts us to question if sex education as 
currently cast is adequate to educating for sexual autonomy today. In making choice central, at issue here is how young people can be educated to make informed, considered choices. While Archard's view is largely in line with present sex education practice, we will suggest that it may be necessary to adjust our views of what young people need to know, discuss and evaluate at different ages and stages if that is to accord with the realities of their lives. Informed choice, premised on our account of personhood and relational autonomy, will only be facilitated by sex education courses that stress the importance of relationships, dignity, respect and non-instrumental interactions, helping young people to think critically about sex, satisfaction and pleasure, sexualisation, sexualised products and images, and gender inequality. Some of these aims are discernible in the UK's sex education policies and guidance. However, teachers in schools and parents and carers may be ignorant or frightened of discussing, for example, internet pornography and social media that convey potentially exploitative messages. By failing to address these features of contemporary culture they may, in turn, contribute to the normalisation of the sexualisation and heteronormative gendering of young people.

Making informed choices about sex will require that an individual is in a position to weigh up the available options without coercion and in ways that align with her own sense of self, her values and her life plans. That sense of self will, in turn, be influenced by her prevailing environment. Her choices will, inevitably, be influenced by peers, a sense of what is and is not 'normal', and by the attitudes and values espoused in her environment, including family, friends and school. Hence we turn, now, to a discussion of that environment.

\section{A sexualised landscape}

The terrain on which sex education is located has changed significantly since Archard's (2000) call for it to enable informed choice. Many feminists have noted with concern, for example, the rise of moral panics over feminine sexuality (Ringrose, 2014), under-theorised notions of ‘sexualisation’ (Albury and Lumby, 2010; Atwood and Smith, 2011; McLelland and Fine, 2014), and the gendered assumptions in many of the official reports and media on male agency and girls’ non-agentic passivity (Coy and Gardner, 2010). These moralising, class based and gendered discourses are reflected in SRE (Ringrose, 2014), which is organised, for the most part, on refusal skills and the avoidance of risk and disease. Rarely, if at all, does SRE focus on choices with regard to sexual pleasure or explore heteronormative assumptions about sexuality, family, marriage, or gender binaries. At the same time, and as noted, the UK has been forced to confront sexual exploitation and abuse, 
of both sexes, in a number of cities and across a range of institutions. Initially, we consider one recent case to illustrate the terrain that has brought sex to the attention of the public and to show how the concept of 'choice' can be misunderstood.

We noted earlier that nine men were found guilty of participation in a gang that sexually exploited under-age girls in Rochdale. A review by the Rochdale Borough Safeguarding Children Board (RBSCB, 2012) drew on the case study of 'Suzie', a victim of sexual exploitation since 2008, acknowledging that relevant children's services and the criminal justice system had failed to support and protect her or to bring her abusers to justice. In common with at least 50 other young people, mainly girls, Suzie was deemed to be making her own choices and the sexual activity was judged to be consensual (RBSCB, 2012, p.9). By the age of 16, Suzie had been seduced by pretences of affection and material inducements, including drugs and alcohol that undermined her capacity for autonomous judgement, and had been coerced into prostitution. Suzie was forced to have sex with five men each day, at least four times a week. Suzie had not engaged in consensual sexual activity. Neither had she been making choices that were autonomous or that expressed her wishes and preferences. Suzie’s bodily integrity and freedom were violated: she and others were used as instruments, as tools for others' ends. Not only was the autonomy of Suzie and numerous other young women denied, her status as a person and respect for her personhood were violated, first by her abusers, and secondly by those to whom she turned for support. As minors, the claim that the victims were making choices has no legal or moral standing. It is an 'assuaging fiction' (Nussbaum, 1999, p.233) to affirm young people’s autonomy by appealing to their supposed lifestyle choices, or to their 'wilful', 'problematic' behavior. It is a poor reason for inaction, and an unacceptable excuse for adults to ignore their moral and legal responsibility to intervene. ${ }^{7}$

In an independent investigation of the sexualisation of young people and violence against women, sexualisation is understood as 'the imposition of adult sexuality on to children and young people before they are capable of dealing with it, mentally, emotionally or physically' (Papadopoulos, 2010, p.6). Pointing to the proliferation and accessibility of sexual, sometimes pornographic, media content in the UK, Papadopoulos argues that not only may this be jeopardising the mental and physical wellbeing of young people (p.17), but that with 'proliferation comes normalisation' (p.7). She concludes that 'many of the choices now available to young girls encourage them to engage and experiment with themes that they may not be cognitively or developmentally ready to engage with' (Papadopoulos, 
2010, p.39). This necessitates a consideration of an 'age and stage' view of readiness with respect to education about sex, a consideration that is noted in UK school sex education policies. However, that young people may not be deemed ready to engage with the sexualised environment is, surely, no reason to ignore that environment and the challenges and opportunities it presents for choice.

Arguably, young people are free to choose whether or not to engage in viewing and participating in sexual objectification, including pornography, but hyper-sexualisation could be co-opting the discourse of freedom and choice. This supports our insistence that relational autonomy is necessary to our account of choice. Young people may be opting for behaviours and appearances that approximate to what they perceive as 'normal'. The sexualised images that surround young people represent a 'monolithic view of the "ideal" women' that may be 'limiting, rather than increasing, the choices open to young girls' (Papadopoulos, 2010, p.62). Choice, in an increasingly sexualised environment, may be reinforcing gendered stereotypes. The struggle for sexual freedom may have turned back on itself with some young people, of all sexual orientations, potentially constrained by conformity to attitudes that drive notions of what is normal and acceptable. By growing up in these contexts, boys and girls may have internalised the norms that might oppress them.

The Bailey Report (2011), addressing the role of media in the sexualisation of UK children's lives, offers further confirmation that young people feel pressurised to become sexually active 'before they are ready to do so' (Bailey 2011, p.6). That Report also focuses on choice, recommending, for example, that internet providers should better facilitate blocking and filtering of material thereby ensuring parents 'must make an active choice over what sort of content they want to allow their children to access' (p.15). So choice here is recommended for parents, carers and teachers in schools who can choose to restrict young people's access to some sexualised images, videos and advertisements. However, many young people will choose to access such material by other means and, importantly, the Bailey Report reminds us that sexually explicit advertisements in public spaces offer no choice. While the link between the sexualisation of culture through the media and harm to children is contested (Smith, 2010), there is a role for schools in helping children to interpret and filter content through media and gender studies and via sex education embedded in the curriculum. Specialist training for teachers is recommended, as is a role for parents in helping children to respond to commercial sexualisation and gender stereotyping. Developing the capacity to make informed choices is critical and, as we will show below, 
sex education policies in the UK emphasise that. However, the choices confronting young people today may be very different from the choices those adults charged with sex education might have experienced, and they may be very different from the choices those adults deem desirable. Autonomous informed choice about sex has become more complex than ever.

Less sensational or public, but arguably more pervasive than the Rochdale or Rotherham cases, 'sexting' on mobile devices, including sharing and distributing sexual images, exemplifies the everyday sexualised terrain on which young people will make choices. A recent study of sexting showed girls more adversely affected than boys with clear evidence of the 'age-old double standard, by which sexually active boys are to be admired and "rated”, while sexually active girls are denigrated and despised as "sluts" ' resulting in 'gender specific risks where girls are unable to speak openly about sexual activities and practices, while boys are at risk of peer exclusion if they do not brag about sexual experiences’ (Ringrose et al., 2012, p.7). Sexting raises complex issues with respect to choice, relational autonomy and ideas of what is 'normal'.

If a young woman sends a nude picture of herself to her partner ${ }^{8}$, is she self-governing to the extent that she is making an informed choice? On one account she may be if there are morally acceptable options available to her: she is choosing freely to send the picture, she has weighed the character of the recipient and assessed the risks. No coercive pressure has been applied, she trusts her partner to be a person who will respect her person and keep the picture private. Even so straightforward a case raises questions of choice. Why does she want to send a nude picture? Is this self-expression, a statement by a girl comfortable with her body? Or is she sending the picture because this is what her friends do: it is a 'normal' thing to do? How can she know her image will not later be posted on social media as retribution for a break-up of the relationship? Has she really thought about the risks and, if the picture does become public property, has she the moral, emotional resources to cope with its dissemination? These are complex issues that demand context sensitive responses and a degree of moral literacy. If she sends the picture because this is what her friends are doing, she is not truly selfgoverning but complying with peer pressure having internalised what she thinks is normal and acceptable behaviour. The choice here might be construed as misinformed or deformed (harmful) desire to comply and be accepted. If she sends the picture 
because her boyfriend is putting pressure on her, she is yielding after, let us assume, some reflection. Perhaps she feels she has no choice if she is to maintain the relationship and she may want to be admired and desired. In this case she might be engaged in less global deliberation, focusing only on her immediate needs to the detriment of weighing up the long-term risks. She surrenders her autonomy. Of course, the case becomes clearer if she becomes subject to intense pressure to send the picture. If she does not yield to pressure, she must find the strength of character to finish the relationship, withstand the pressure, or make her partner understand that this persistence is harmful. If she ends the relationship because she values her own selfworth and recognises that this is unfair pressure, she keeps her autonomy intact.

Such an example signifies the dynamic relationship between social and individual contexts of sexting and autonomous choice, and practices which might be judged oppressive. Cudd (2006, p.183) suggests that deformed desires can be mistaken for 'legitimate expressions of individual differences in taste' when in fact they are 'formed by processes that are coercive: indoctrination, manipulation and adaptation to unfair circumstances'. Girls may feel coerced into forms of hyper-femininity, into 'girl typing' (Lamb and Brown, 2006, p.20) in which sending nude pictures may be a manifestation. Alongside public cases of sexual exploitation, the reports and examples cited here indicate that today's sexualised culture impacts on all sexes and will affect constructions of masculinity and femininity, potentially constraining the autonomy of young people. Today's so-called 'girl power' may be as constraining as it is empowering. MacKinnon (1991, p.124) claimed that 'women have been the nature, the matter, the acted upon to be subdued by the acting subject'. Suzie was acted upon. So too, though less extremely, are young women whose choices may be circumscribed by an environment in which men regard women's bodies as commodities for their use and pleasure, and in which women may feel pressurised to define themselves largely on the basis of sexual attractiveness and activity. Education about sex should, we propose, focus on deliberations about the sexualised landscape of young people today. For all sexes and sexualities, the evidence indicates how formidable is the task of sex education with respect to autonomous choice and so we turn, now, to a consideration of current policy and guidance on sex education in UK schools.

Sex education in the United Kingdom 
Article 17 of the UN Convention on the Rights of the Child states that 'children and young people have a right to information that is important to their health and wellbeing', and Article 34 requires governments to protect children 'from all forms of sexual exploitation and abuse' (United Nations, 1989). In January 2014, the House of Lords debated amendments to the Children and Families Bill which, had they been accepted, would have made SRE compulsory in all schools (House of Commons, 2015, p.5) with the House of Commons Education Committee reporting significant support for statutory provision (p.47). However, the right of parents to withdraw their child from SRE aligns with Article 2 of Protocol 1 of the European Convention on Human Rights: 'the State shall respect the right of parents to ensure such education and teaching is in conformity with their own religious and philosophical convictions' (Council of Europe, 2010, p.32). That right prevailed.

In England, primary schools are not required to provide SRE beyond the National Curriculum for science, and governing bodies and headteachers can decide whether SRE should be included in the school's curriculum. Maintained secondary schools are required to cover sexually transmitted diseases as part of the National Curriculum for science at Key Stage 4. Academies do not have to provide SRE (House of Commons, 2015, p.46). Sex education is not a statutory requirement in maintained secondary schools but they are required to offer SRE, including, minimally, information about sexually transmitted infections and HIV/AIDS. These are factually based SRE programmes. Additional Personal, Social, Health and Economic Education (PSHE) is not mandatory (FPA, 2011), although the Department for Education (2010, p.46) notes that children should have 'high-quality sex and relationships education in order to make 'wise and informed choices'.

Relationships and Sexuality Education (RSE) is a legal requirement in Northern Ireland ${ }^{9}$ and is taught as part of the Science curriculum. Sex education is also mandatory in Wales with SRE designed to enable children to make 'safe and responsible choices regarding their sexual behaviour' (Welsh Assembly Government, 2010, p.8). Guidance in Scotland expects schools to provide Relationships, Sexual Health and Parenthood (RSHP) education although this is not a statutory requirement (Scottish Government, 2013a, point 15). Schools and authorities are to be sensitive to parental/carer wishes to withdraw their child from all or part of a sexual health education programme although the views of the child should be 'taken into account, given their statutory right to an education' (Scottish Government, 2013a, point 16). It is acknowledged that RSHP will feature across much of 
the curriculum and Scotland's draft guidance cautions that withdrawing children may not be possible if that prevents ‘an adequate and holistic education’ (Scottish Government, 2013a, point 16). The Health and Wellbeing area of Scotland's Curriculum for Excellence ${ }^{10}$ attends to relationships, sexual health and parenthood with respect to media awareness and critique. RSHP stresses the centrality of 'sound values and an awareness of the law on sexual behaviour', 'the values of a stable and loving family life', 'the value of commitment in relationships', 'self-restraint, dignity and respect for themselves and the views of others', a recognition of 'the risks, the physical, emotional and moral implications of certain types of behaviour' and the 'responsible behaviour' of both sexes (Scottish Government, 2013a). Overall sex education aims to help young people make 'informed, responsible and healthy choices about their lives’ (Scottish Government, 2014b). All of these policies highlight choice but do they go far enough towards teaching autonomous choice about sex that enables young people to flourish in today’s environment?

Young people consulted during the Jay Inquiry (2014) offered scathing comments about the sex education they received at school. They complained that, focussed only on contraception, sex education was out of touch and needed to be updated. They also complained that choice, under the guise of cultural, faith and ethnic sensitivity may also be contributing to effectively limiting their choice about sex. Despite increasing calls to make sex education compulsory across the UK, parental rights to withdraw their children from sex education (apart from lessons focussed on biology and health) prevail (House of Commons Education Committee Report ${ }^{11}$, 2015, p.56). That right of withdrawal may not be in the best interests of young people, especially if it means they are excluded from deliberation that might inform their understanding and capacity to make the kinds of wise, safe, and informed choices desired by policy. In allowing SRE to be controlled by parents and carers, some young people may be disadvantaged, receiving only the facts about sex which represent, as noted earlier, at the very least too little too late and, at worst, inadequate consideration of the context in which they are likely to need to make choices. SRE which encourages discussions on the contexts conducive to or inhibiting of sexual pleasure and safety, sexual practices supporting or inhibiting sexual pleasure for all genders and sexual orientations, would more likely encourage young people to think about safe and respectful sex. Such discussions would necessarily cover notions of consent, coercion, power and rights (Hirst, 2014). Affording parents and carers the choice to remove their children from education about sex may mean that their children are denied the opportunity to learn to deliberate and choose for themselves. Hence, we contest any opt-out from the education 
about sex that currently applies to religious, cultural or ethnic groups. In so doing, we note a degree of support for this argument from sections of those communities who might choose to withdraw their children from such lessons.

Drawing on cases explored in the UK Muslim Women’s Network research, Gohir (2013) recommends awareness raising of child sexual exploitation before secondary school. Gohir (2013, p.30) insists this should include relationship education to 'foster respect for women and girls aimed to promote healthy relationships and a better understanding of what constitutes consent'. Additionally, the Jay Inquiry pointed to the likely under-reporting of exploitation and abuse in minority ethnic communities and the BBC has reported that 'the culture of honour and shame protecting these cases’ results in under-reporting. ${ }^{12}$ Not only might those abused feel unable to seek support from their own families and cultural and religious communities, but they might also be excluded from SRE because of the rights of their parents/carers to withdraw them from such education. So UK policy continues to deny young people the very sex education that might enable them to be confident that sexual exploitation of any sort represents an abuse of their right to make autonomous choices. An education about sex and relationships that has, at its core, a focus on autonomous choice and respect, for self and all others, should surely transcend personal, cultural and faith boundaries, just as sexual abuse and exploitation and changing norms transcend those boundaries.

As currently formulated the guidance on sex education is over-cautious, safe but banal, and it seems likely to fall short of educating for autonomous choice in today's sexualised environment. For example, many teachers of SRE would likely not feel comfortable focussing on sexual experimentation, partly because experimentation is rarely seen as a positive part of young people’s sexual repertoire. Yet, as Hirst (2014, p.44) comments, sexual experimentation can be pleasurable and health protecting and it can challenge heteronormativity. Informed non-gendered sex education will recognise young people as sexual persons. However, if it remains under-specified and under-resourced (Archard, 2000), then it may allow too much discretion for schools to limit the amount of information and discussion provided. Our scepticism that current practice may not be adequate arises not only from the generous provision for parents to withdraw their children from even the limited curricular provision now in place in the UK. It emerges, too, against the backdrop of evidence that many adults appear to be out of touch with the extent to which children feel pressurised to engage in sexual practices, needing to make choices quite distinct from those adults may have experienced at a similar age. To develop our proposals for relevant 
education about sex we return to our starting point, to Archard's (2000) philosophical treatment of the challenges of providing sex education fit for purpose today, with a central role for choice in sexual morality and literacy.

\section{Defending choice in education about sex}

Enabling young people to make autonomous choices about sex will be challenging. Meeting such challenges will require educators to understand the realities of young people's lives, to appreciate the complexities of relational autonomy, and to work towards a view of personhood that affords respect and dignity to all. Until recently, gender discrimination, sexism, sexual assault and harassment and the rights of children were rarely discussed because they were not recognised as features of the moral terrain. However, the authorities' knowledge of what may have been going on in the Rochdale and similar cases has brought bad sex to the fore rendering it, potentially, morally salient to all. It should be possible to discuss with young people what they might deem to be 'a certain conception of morally good sex, that is, a coherent set of moral principles to which sexual activities should comply' (Steutel and Spiecker, 1996, p.400). Deliberations on morally good sex would be informed by a concept of personhood in order that choices respect the autonomy of others. Thereby young people themselves would be encouraged to 'specify what it means to care for the well-being or to respect the dignity of human beings in the sexual sphere of life' (Steutel and Spiecker, 1996, p.401).

However, determining what conditions would need to be met to ensure autonomous informed choice for morally good sex in the kinds of situations in which young people find themselves today is not straightforward. We concede the possibility that under some extreme conditions deciding to succumb to coercion could be an informed choice. Threats of further violence or blackmail, for example, might result in a choice to conform to the wishes of abusers. While such a choice may be informed it is not autonomous. The term 'informed choice' itself can also be problematic if it is interpreted as largely a matter of providing information about, for example, the biology of reproduction, contraception and sexually transmitted infections. We have acknowledged that being informed requires more than mere facts. On the strength of our discussion so far, a curriculum that is up to the task of educating young people will include a strong and critical focus on the media's projection of sexual ideals, the use of social media and ways in which gender and culture influence sexual behaviour. Informed choice needs to be located in an environment that provides 
opportunities for young people to deliberate on choice and the range of options and possibilities their everyday realities offer.

A sexualised and potentially exploitative environment reveals competing moral claims from parents, faith groups and schools that require evaluative principles to guide deliberation. The approach we advocate needs to be underpinned by moral literacy, the 'basic learned capacity to acquire and use moral knowledge in judgement and action' (Herman, 2008, p.80). Rather than an education in restraint, moral literacy might enable young people to read their environment in ways that help them to value the justification of motives and actions, assisting them, in the process, to reformulate or adjust their wishes, desires, beliefs and attitudes. Moral literacy would also consider what it means to judge certain sexual behaviours as 'normal'.

Deliberation on personhood, choice and moral salience might occupy centre stage in an education that focuses on the development of moral literacy across the curriculum rather than exclusively in sex education slots on a timetable. Young people of all sexes and any sexuality might then be better equipped to judge how media images, sexual abuse and exploitation cases, and apparent expectations about ways in which young people should behave sexually, might support or infringe the concepts of personhood we have sketched here. Building from Burkett and Hamilton’s (2012, p.830) call to reconnect 'popular understandings of sex with issues of power, gender and sociocultural norms', sex education might examine vulnerability and potential exploitation. Young people would be encouraged to articulate their views about morally good sex and the entitlement of each individual to make choices, free from coercion. Examples drawn from the media and sexist advertisements could encourage discussion of ways in which the eroticisation of, usually, women maintains asymmetries of power and heteronormative gender distinctions. Dworkin (1987, p.92) famously noted that the 'brilliance of objectification as a strategy of dominance is that it gets the woman to take the initiative in her own degradation' so taking the blame for her choice. Young women might be asked to examine the extent to which their desire to be attractive to others might mean they are colluding in their own degradation and, in effect, internalising a form of female misogyny. Young men would be asked to examine the extent to which feelings of entitlement to women as sexual objects to satisfy their own desires might mean they are colluding in the oppression of those young women and, in effect, internalising a form of male hegemony. However, to do so, it would be important to accept that young people may, after deliberation and in full knowledge of the facts, make informed choices that are not ones with which others might agree. 
All young people are potentially at risk of sexual exploitation and hence of deformed or adaptive rather than informed choice, but for as long as that exploitation remains hidden, sexually exploitative experiences will continue to cause physical, mental and emotional damage. While we are not suggesting schools alone can protect young people and enable them to be autonomous choosers with regard to their sexual behaviours, schools do provide an important setting in which to focus on the realities of young people's lives and the difficult choices they need to make.

If sex education is neither a separate nor a minor, low status part of the curriculum then our young people might be allowed to reclaim equality and liberation from sexual behaviours they have not so much chosen as had foisted upon them. Such an education might better equip both young women and men to exercise informed choice in a sexualised landscape in which, from 'a young age, boys are taught that they are entitled to consume women's bodies' whilst 'girls are encouraged to embrace this as liberating' (Taylor, cited in Papadopoulos, 2011, p.46). We are proposing a revised, less cautious and less banal form of sex education in the UK to more successfully educate young people for a sexualised world by directly addressing the issues and likely choices that face them. Our claim is that much can be done to make the current approach more appropriate to the conditions it needs to address.

Note: The authors would like it to be known that each contributed equally to the paper.

\section{References}

Allen, L.E., Rasmussen, M., and Quinlivan, K. (Eds)(2014) The Politics of Pleasure in Sexuality Education: Pleasure Bound (New York: Routledge).

Archard, D. (2000) Sex Education Impact 7 (Philosophy of Education Society of Great Britain: Wiley Blackwell). Available at: http://onlinelibrary.wiley.com/doi/10.1111/j.2048-416X.2000.tb00055.x/abstract

Atwood, F. and C. Smith (2011) Lamenting sexualisation: Research, rhetoric and the story of young people's 'sexualisation' in the UK Home Office Review', Special Issue 'Investigating Young People's Sexual Cultures', Sex Education 11(3), 327-37.

Bailey, R. (2011) Letting children be children: Report of an independent review of the commercialisation and sexualisation of childhood, Department of Education. Available at: http://www.education.gov.uk/inthenews/inthenews/a0077662/bailey-review-of-thecommercialisation-and-sexualisation-of-childhood-final-report-published

Berelowitz, S., Firmin, C., Edwards, G. and Gulyurtlu, S. (2012) 'I thought I was the only one. The only one in the world'. Inquiry into child sexual abuse in gangs and groups. Interim Report, Office of the Children's Commissioner. Available at: http://www.childrenscommissioner.gov.uk/info/csegg1

Blackman, S. (2004) Chilling Out: The Cultural Politics of Substance Consumption, Youth and Drug Policy (Open University Press: Maidenhead). 
Buckingham, D., Willett, R., Bragg, S. and Russell, R. (2010) Sexualised Goods Aimed at Children: A Report to the Scottish Parliament Equal Opportunities Committee. Scottish Parliament Equal Opportunities Committee (Edinburgh, UK). Available at: http://oro.open.ac.uk/25843/2/sexualised_goods_report.pdf

Cudd, A. (2006) Analysing Oppression (Oxford, New York: Oxford University Press).

Dworkin, A. (1987) Intercourse (New York: Basic Books).

Gohir, S. (2013) Unheard Voices: The Sexual Exploitation of Asian Girls and Young Women. Available at: http://www.mwnuk.co.uk//go_files/resources/UnheardVoices.pdf

Friedman, M. (2003) Autonomy, Gender, Politics (Oxford: Oxford University Press).

Herman, B. (2008) Moral Literacy (Cambridge: Harvard University Press).

Hirst, J. (2014) 'Get some rhythm round the clitoris': Addressing sexual pleasure in sexuality education in schools and other youth settings. In: Allen, L.E., Rasmussen, M., and Quinlivan, K. (Eds)(2014) The Politics of Pleasure in Sexuality Education: Pleasure Bound (New York: Routledge), 35-56.

House of Commons, Education Committee (2015) Life Lessons: PSHE and SRE in Schools, Fifth Report of Session 2014-15, (London: Stationary Office). Available at: http://www.publications.parliament.uk/pa/cm201415/cmselect/cmeduc/145/145.pdf

Jay, A. (2014) Independent Inquiry into Child Sexual Exploitation in Rotherham 19972013. Rotherham Metropolitan Borough Council. Available at: http://www.rotherham.gov.uk/downloads/file/1407/independent_inquiry_cse_in_rotherh am

Lamb, S. (2010) Towards a sexual ethics curriculum: Bringing philosophy and society to bear on individual development, Harvard Educational Review, 80(1), 81-105.

Lamb, S. and Brown, L. (2006) Packaging Girlhood: Rescuing Our Daughters from Marketers' Schemes (St Martins Griffin: New York).

Lumby, C. and Albury, K. (2010), "Too Much? Too Young? The Sexualisation of Children Debate in Australia", Media Information Australia, 135, 141-152.

McClelland, S.I and Fine, M. (2014) 'Over-sexed and under surveillance: Adolescent sexualities, cultural anxieties and thick desire’. In: Allen, L.E., Rasmussen, M., and Quinlivan, K. (Eds)(2014) The Politics of Pleasure in Sexuality Education: Pleasure Bound (New York: Routledge), 12-34.

MacKenzie, C. and Stoljar, N. (2000) Introduction: Autonomy refigured. In C. MacKenzie and N. Stoljar (Eds) Relational Autonomy: Feminist Perspectives on Autonomy, Agency and the Social Self (New York: Oxford University Press), 3-31.

MacKinnon, CA (1991) Towards a Feminist Theory of the State (Cambridge: Harvard University Press).

Mosher, D.L. (1989) Threat to sexual freedom: Moralistic intolerance instills a spiral of silence, The Journal of Sex Research, 26(4), 492-509.

Nussbaum, M.C. (1999) Sex and Social Justice (Oxford, New York: Oxford University Press).

Oerton, S. and Bowen, H. (2014) Key issues in sex education: Reflecting on teaching, learning and assessment, Sex Education, 14(1), 1-13.

Papadopoulos, L. (2010) Sexualisation of Young People Review (Crown Copyright). Available at: http://webarchive.nationalarchives.gov.uk/+/homeoffice.gov.uk/documents/sexualisation -young-people.html

Rawls, J. (1971) A Theory of Justice (Harvard, MA: Harvard University Press).

Renold, E. and Ringrose, J. (2011) Schizoid subjectivities? Re-theorising teen girls’ sexual cultures in an era of 'sexualisation', Journal of Sociology, 47(4), 389-409.

Ringrose, J. (2016) Postfeminist Media Panics over girls' ‘sexualisation’: Implications for UK sex and relationship guidance and education. In: Sundaram, V and Sauntson, H. 
(Eds) Global Perspectives and Key Debates in Sex and Relationships Education Addressing Issues of Gender, Sexuality, Plurality and Power (Palgrave MacMillan), 3047.

Ringrose, J., Gill, R., Livingstone, S. and Harvey, L. (2012) A Qualitative Study of Children, Young People and 'Sexting' (London: NSPCC).

RBSCB (2012) Review of Multi-Agency Responses to the Sexual Exploitation of Children. Available at: http://cdn.basw.co.uk/upload/basw_20640-8.pdf

Shannon, B. and Smith, S.J. (2015) 'A lot more to learn than where babies come from': controversy, language and agenda setting in the framing of school-based sexuality education curricula in Australia, Sex Education, 15(6), 641-654.

Scottish Government (2013a) Draft Guidance on the Conduct of Relationships, Sexual Health and Parenthood Education in Scottish Schools. Available at: http://www.gov.scot/Resource/0046/00465948.pdf

Scottish Government (2013b) Relationships, Sexual Health and Parenthood Education. Available at: http://www.gov.scot/Topics/Education/Schools/HLivi/sex-education

Smith, C. (2010) Review of Papadopoulos participations, Journal of Audience and Reception Studies, 7(1), 175-179.

Steutel, J. and de Ruyter, D. (2009) Compulsory sex education: teaching about the right and the good. Paper presented at the PESGB Annual Conference, Oxford, UK. Available at: http://www.philosophy-ofeducation.org/conferences/pdfs/SteutelDeRuyter.pdf

Steutel, J. and Spiecker, B. (1996) Good sex as the aim of sexual education (F. Margonis, Ed) Philosophy of Education. (Illinois: University Of Illinois, Urbana), 400-407. Available at: http://ojs.ed.uiuc.edu/index.php/pes/article/view/2297

Welsh Assembly Government (2010) Sex and Relationships Education in Schools. Welsh Assembly Government Circular No: 019/2010. Available at: http://learning.wales.gov.uk/docs/learningwales/publications/130425-sex-andrelationships-education-in-schools-en.pdf

World Health Organisation (WHO) (2016) Sexual Health. Available at: http://www.who.int/topics/sexual_health/en/

1 See http://www.parliament.uk/business/committees/committees-a-z/commons-select/educationcommittee/inquiries/parliament-2010/pshe-and-sre-in-schools/.

2 Simon Blake (2012) of Brook, the UK's largest young people's sexual health charity. http://www.sexeducationforum.org.uk/media/17706/sreadvice.pdf

3 And see Lumby and Albury (2010); Renold and Ringrose (2011).

4 We are grateful to an anonymous reviewer for raising this point.

5 The National Survey of Sexual Attitudes and Lifestyles (NATSAL, 2000) noted the average age for initial sexual intercourse was 16 for both men and women. $25 \%$ of men and almost $50 \%$ of women aged between 16 and 24 later regretted not delaying sex.

6 See, for example, the special volume of Gender and Education, 2012, on the sexualisation debates.

7 Rochdale was not an isolated case. The Jay Inquiry (2014) suggests some 1,400 children were abused in Rotherham.

8 The example could equally apply to a young man sending a picture. We do not assume heterosexuality and could apply to a couple of any sexuality.

${ }^{9}$ http://www.fpa.org.uk/sites/default/files/northern-ireland-relationships-and-sexuality-educationin-schools.pdf

10 http://www.educationscotland.gov.uk/learningteachingandassessment/curriculumareas/ healthandwellbeing/index.asp

11 http://www.publications.parliament.uk/pa/cm201415/cmselect/cmeduc/145/145.pdf

12 http://www.bbc.co.uk/news/uk-29794729 